\title{
Soil-Geopolymer Mixtures Using Recycled Concrete Aggregates for Base and Subbase Layers
}

\author{
Daniel Odion ${ }^{1}$, Mohammed $J$ Khattak $^{1 *}$, Makarios Abader ${ }^{1}$, and Nathan Heim ${ }^{2}$ \\ ${ }^{1}$ Department of Civil Engineering, University of Louisiana at Lafayette, Lafayette, LA 70504 \\ ${ }^{2}$ Research Experience for Undergraduates (REU) Participant at UL, University of Alabama
}

\begin{abstract}
The recycling of concrete aggregates has become a viable venture to investigate particularly its application in road construction. This study was conducted to proffer the feasibility of using recycled concrete aggregate (RCA) mixed with soil, flyash and alkali activator as an alternative to soil-cement in road base or subbase applications. The resulting product known as Soil-RCA geopolymer was made by varied mix constituents of flyash, RCA, sodium silicate, and sodium hydroxide. The influence of mixture variables on the mechanical properties of Soil-RCA geopolymer was investigated through an experiment design using two different flyash. Models to predict the unconfined compressive strengths based on mixture parameters were also established for the sensitivity analysis and selection of final mixtures. The results and analysis showed that the Soil-RCA geopolymer mixture exhibited sound strength, stiffness and durability characteristics.
\end{abstract}

\section{Introduction}

Soil stabilization has shown to be economical as it provides cheap materials for the construction of low-cost roads. Portland cement stabilization is one of such methods, which has proven to be effective especially in the case of sandy soil due to the ease of pulverization. The primary reaction of cement is with the water in the soil, which leads to the formation of a cementitious material. Cement stabilized road bases using soil as a constituent, provide substantial support to the overlaying pavement layer thereby reducing stresses on subgrade soil. Thus, the use of soil-cement becomes cost-effective in areas that are deficient in aggregate resources. However, the high carbon footprint and cost of using cement for pavement base/subbase stabilization has led to seeking alternative low-carbon stabilization technique like flyash-based geopolymer. Further, the soil-cement causes shrinkage cracks in the base layer, which appear as reflective cracks in hot mixed asphalt (HMA) that are responsible for low ride quality and moisture damage in pavements [1].

Recycling of concrete aggregates resulting from certain construction processes offers a way to reduce waste disposal loads sent to area landfills and to extend the life of natural resources [1]. Although, many federal and state highway contracts specify the use of recycled materials in highway construction with increasing rate of usage being influenced by the availability, engineering performance, and financial incentives as determined by the marketplace. Hence, it has become essential to utilize the advanced alternate cementing technologies and available RCA to economically produce more durable pavement subbase and bases. One such alternate binding material is known to be flyash-based geopoloymer binders. These are class of materials resulting from industrial by-products with a low carbon footprint. Its use in unbound pavement base/subbase applications has generated growing research interest in recent years. This material has been investigated and it is now widely known that the utilization of geopolymer technology could substantially reduce $\mathrm{CO}_{2}$ with minimum economic detriments $[2,3]$.

Recently, geopolymers have gained prominence attention in the concrete industry, and several research studies have been conducted to address their short and long-term performances [4-10]. Based on the survey conducted in 2013, about $68 \%$ of recycled concrete aggregate (RCA) is used as road base and the remainder is used for new concrete mixes, asphalt hot mixes, highvalue riprap and low-value products like general fill [11]. On the other hand, about $50 \%$ of flyash is used in bound form in concrete products while $27 \%$ is utilized as loose form in structural fills and embankments [12]. More so, several studies have been reported on the improvement of mechanical characteristics of soils using alkali activated flyash-based geopolymers [13-24]. Such studies have proven that the flyash content is vital for the geopolymerization process while the unconfined compressive strength (UCS) of the soil-mixtures increased with increase in flyash content at an optimum of $30 \%$ content [16-18].

This study tends to apply flyash-based geopolymer binder and RCA to stabilize and enhance the durability of pavement soil base and subbases. The objectives of the study are:

\footnotetext{
* Corresponding author: khattak@louisiana.edu
} 
- Evaluate the effect of various Soil-RCA geopolymer mixture components on the UCS and elastic modulus of the mixtures.

- Compare the strengths and durability characteristics of the selected Soil-RCA geopolymer and soilcement mixtures.

\section{Materials and methods}

\subsection{Material systems}

The soil was sourced from a construction site in Louisiana. After the Atterberg limits test as per ASTM D-4318 procedure was conducted, the LL, PL, and PI of the soil were found to be $36.9,18.8$, and 18.1, respectively. Based on the AASHTO and Unified Classification systems, the soil was classified as Lean Clay and A-6 with composition as shown in Table 1. Two different Class F flyash (FA) types namely Salt Lake River (SL) and Boral Flyash (BR) were used. Class $\mathrm{F}$ flyash has little calcium in it, and therefore requires an alkali to activate its cementitious properties. The RCA was sourced from a local contractor. The compositions of flyash, soil, and RCA are shown in Table 1.

Table 1. Elemental composition of flyash, soil, and RCA.

\begin{tabular}{|c|c|c|c|c|c|}
\hline \multicolumn{2}{|c|}{ Element } & SL- Flyash & BR-Flyash & Soil & RCA \\
\hline \multirow{2}{*}{} & $\mathbf{C}$ & - & - & 16.20 & - \\
\cline { 2 - 6 } & $\mathbf{O}$ & 15.57 & 18.74 & 22.40 & 21.20 \\
\cline { 2 - 6 } & $\mathbf{N a}$ & 0.50 & - & - & - \\
\cline { 2 - 6 } & $\mathbf{M g}$ & - & 1.26 & - & 0.30 \\
\cline { 2 - 6 } & $\mathbf{A l}$ & 6.480 & 17.07 & 9.770 & 4.020 \\
\cline { 2 - 6 } & $\mathbf{S i}$ & 52.71 & 44.50 & 43.16 & 34.38 \\
\hline \multirow{2}{*}{} & $\mathbf{S}$ & 0.31 & - & - & 0.76 \\
\cline { 2 - 6 } & $\mathbf{K}$ & 5.57 & 1.36 & 2.49 & 0.79 \\
\cline { 2 - 6 } & $\mathbf{C a}$ & 7.200 & 10.21 & 0.93 & 32.52 \\
\cline { 2 - 6 } & $\mathbf{F e}$ & 8.29 & 5.93 & 4.97 & 2.76 \\
\cline { 2 - 6 } & $\mathbf{T e}$ & 3.47 & - & - & 3.13 \\
\hline \multirow{2}{*}{} & & & & & \\
\hline
\end{tabular}

Alkali solution with sodium hydroxide $(\mathrm{NaOH})$ and sodium silicate $\left(\mathrm{Na}_{2} \mathrm{SiO}_{3}\right)$ as main constituents was used as an activator. The alkali activator was prepared by mixing required proportions of $\mathrm{Na}_{2} \mathrm{SiO}_{3}$ and $6 \mathrm{M} \mathrm{NaOH}$ as specified in the mix design. Sodium-based solutions were chosen because they are cheaper and because it is reported that $\mathrm{NaOH}$ possesses greater capacity to liberate silicate and aluminate monomers when mixed with flyash. Additionally, Portland cement was used for preparing the soil-cement mixtures.

\subsection{Optimum moisture content and maximum dry density}

The optimum moisture content (OMC) and maximum dry density (MDD) were determined using the modified proctor test following ASTM D-1140 and ASTM D1557 procedures. The MDD was shown to be higher for mixtures, which contained only soil (Table 2). This indicates that the low density of the flyash had a higher effect on the MDD than the high-density RCA. At the same time, as the minority constituents increased, the OMC slightly increased, leveling off at about $14 \%$ for SL but showed $11 \%$ for BR flyash. Apparently, the MDD of RCA mixture for BR flyash was higher than that of SL flyash mixtures as noticed.

Table 2. Maximum Dry Density and Optimum Moisture Content.

\begin{tabular}{|c|c|c|c|c|}
\hline \multirow{2}{*}{ Mixture Type } & \multicolumn{2}{|c|}{$\begin{array}{c}\text { Salt Lake River } \\
\text { Flyash (SL) }\end{array}$} & \multicolumn{2}{c|}{$\begin{array}{c}\text { Boral Flyash } \\
\text { (BR) }\end{array}$} \\
\cline { 2 - 5 } & $\begin{array}{c}\text { MDD, } \\
\text { g/cm }\end{array}$ & $\begin{array}{c}\text { OMC, } \\
\mathbf{\%}\end{array}$ & $\begin{array}{c}\text { MDD, } \\
\mathbf{g}_{\mathbf{c}} \mathbf{c m}^{\mathbf{3}}\end{array}$ & $\begin{array}{c}\text { OMC, } \\
\mathbf{\%}\end{array}$ \\
\hline 0\%FA-0\%RCA-Soil & 1.90 & 13.8 & 1.90 & 13.8 \\
\hline 15\%FA-15\%RCA-Soil & 1.79 & 14.1 & 1.87 & 11.5 \\
\hline 25\%FA-25\%RCA-Soil & 1.75 & 14.0 & 1.81 & 11.0 \\
\hline
\end{tabular}

\subsection{Specimen preparation}

The requisite quantity of soil weighed to the nearest gram was oven dried for $24 \mathrm{~h}$ at $110 \pm 5^{\circ} \mathrm{C}$ and then thoroughly mixed with source materials until a uniform mix was obtained. All samples were made by mixing dry constituents of soil, FA, RCA with alkali solution based on the OMC. These were molded into cylindrical specimens of $72 \mathrm{~mm}$ diameter and $144 \mathrm{~mm}$ height after compaction at MDD according to ASTM D1557 procedure with slight modification. This mixture was poured into a cylindrical mold in three equal layers. Each layer was rodded 25 times to get the aggregates settled before further compaction with the aid of a 6-ton compress. The specimen was then extruded to about 1-2 $\mathrm{mm}$, trimmed and stored in a sealed plastic mold before being cured for $72 \mathrm{~h}$ at $60^{\circ} \mathrm{C}$. Preliminary testing showed that the UCS of the mixture increased with the increase in oven curing time and at $72 \mathrm{~h}$ the UCS plateaus with minimum rate of strength gain.

\subsection{Experiment design}

An experimental design matrix was developed to find the optimum mix based on UCS of the mixtures. This design covered varying dosages of flyash $(5 \%, 15 \%$ and $25 \%)$, Alkali as a mixture of $\mathrm{Na}_{2} \mathrm{SiO}_{3}$ and $6 \mathrm{M} \mathrm{NaOH}$ with varying $\%$ of $\mathrm{Na}_{2} \mathrm{SiO}_{3}(0,33 \%$, and $50 \%)$, and $\mathrm{RCA}$ content $(5 \%, 15 \%$, and $25 \%)$. Based on these varying content mixtures, a total of 13 Soil-RCA geopolymer were prepared in triplicate specimens and tested using the following mechanical tests.

\subsection{Unconfined compressive strength (UCS)}

The cured specimen of $72 \mathrm{~mm}$ diameter and $144 \mathrm{~mm}$ height was loaded axially under compression until failure. The test continued at a loading of $5 \mathrm{~mm} / \mathrm{min}$ until load values decrease or until $20 \%$ strain is reached. This test was conducted in accordance with ASTM D2166 procedure. Real time strain and load data acquisition was conducted at an equal time interval with the aid of an extensometer that was attached at mid-third of the specimen. The compressive load at failure was recorded and the UCS was calculated as: 


$$
U C S=P / A
$$

Where, $\mathrm{P}$ is maximum load at failure $(\mathrm{N})$ and $\mathrm{A}$ is cross sectional area of sample $\left(\mathrm{m}^{2}\right)$.

The modulus of elasticity (E) was found by calculating the slope of the linear portion of the stressstrain curve, usually up to one-third of the UCS.

\subsection{Indirect tensile strength (ITS) test}

The indirect tensile strength $\left(\mathrm{S}_{\mathrm{t}}\right)$ of the cylindrical specimens $101 \mathrm{~mm}$ diameter and $64 \mathrm{~mm}$ thick was determined using the procedure outlined in ASTM D6931. The specimens were loaded along a diametric plane with a compressive load at a constant rate of 25.4 $\mathrm{mm} / \mathrm{min}$ acting parallel to and along the plane. A 12.5 $\mathrm{mm}$ wide strip loading was used to provide a uniform loading with which produces a nearly uniform stress distribution. The peak load was recorded and the ITS was calculated using the following equation:

$$
S_{t}=2 P / \pi \mathrm{tD}
$$

Where, $\mathrm{S}_{\mathrm{t}}$ is indirect tensile strength $(\mathrm{Pa}), \mathrm{P}$ is maximum load $(\mathrm{N}), \mathrm{t}$ and $\mathrm{D}$ are the specimen height diameter of specimen in meters $(\mathrm{m})$.

\subsection{Durability test}

Durability Test. The durability specimens were made and tested in accordance to ASTM D559 standard procedure. In this test, the specimen was submerged in water for $5 \mathrm{~h}$ and dried in oven at $71 \pm 3^{\circ} \mathrm{C}$ for $43 \mathrm{~h}$ to make one cycle with the mass, and volume recorded for each cycle. The test was conducted for 12 cycles.

\section{Results and discussion}

\subsection{Effect of FA content}

Figure 1 shows the variation of UCS and E values of specimens with FA content at 15\% RCA, and 33\% alkali mixture with $33 \% \mathrm{Na}_{2} \mathrm{SiO}_{3}$. As the BR flyash content increased to $5 \%$, the UCS was found to be increased beyond $100 \%$ while $\mathrm{E}$ value rose by $50 \%$ relative to the control one (soil only). The UCS and E values continuously increased with the increase in FA content, which could be attributed to the availability of more geopolymer binder in the mixture particularly at $25 \% \mathrm{FA}$ content. On the other hand, the specimens of SL flyash did not show much increase in the UCS and E values after 15\% FA content. FA content beyond 5\% exhibited same increases in UCS, as that of the BR flyash but the resulting E was different for both flyashes. Apparently, the mixture with BR flyash yielded more UCS and E values. The deviation on the $\mathrm{E}$ for the $\mathrm{BR}$ flyash at $25 \%$ FA content is quite noticeable (see Figure 1). This is an outcome of a poor sample preparation on one of the three specimens tested. In general, the coefficient of variation ranged from 5 to $20 \%$.
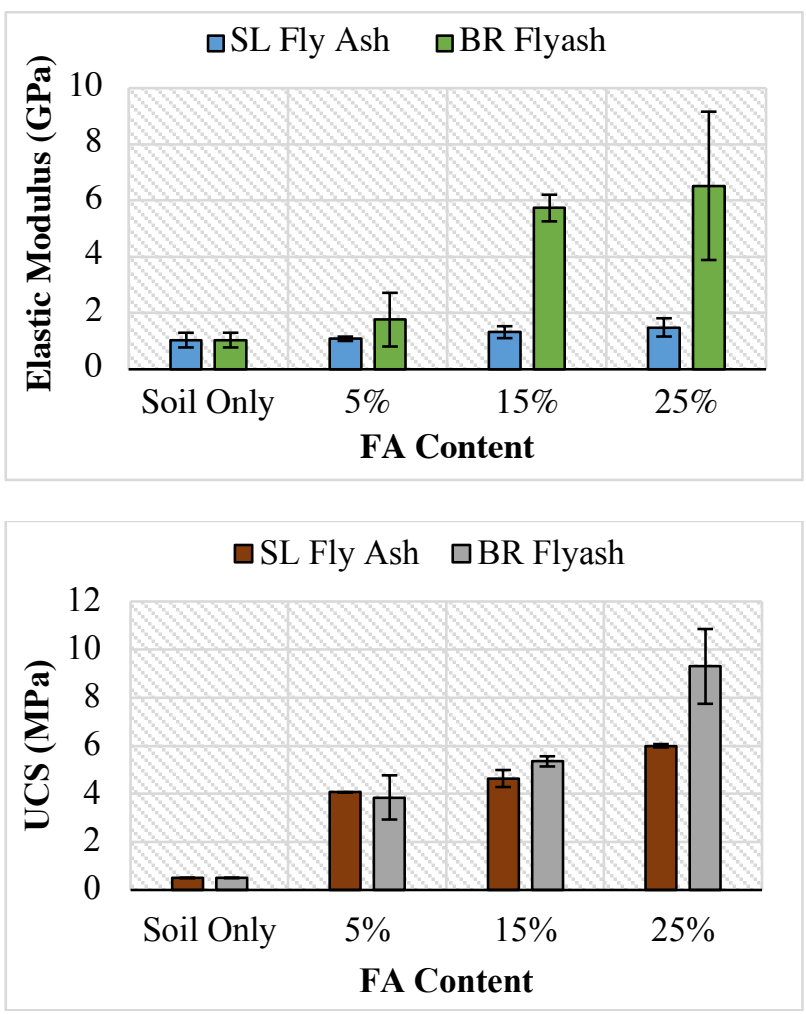

Fig. 1. Effect of flyash content on E and UCS at 15\% RCA and $33 \% \mathrm{Na}_{2} \mathrm{SiO}_{3}\left(72 \mathrm{~h}\right.$ at $\left.60^{\circ} \mathrm{C}\right)$.

\subsection{Effect of RCA content}

According to the Figure 2 below, both the BR and SL flyashes showed opposite trends in response to increase in RCA contents at $15 \%$ fly ash and $33 \% \mathrm{Na}_{2} \mathrm{SiO}_{3}$. While the former decreased with RCA values, the later increased with both having similar values at 15\% RCA. The BR flyash had the highest UCS value at $5 \% \mathrm{RCA}$ as compared to SL with $25 \%$ RCA. However, the E of SL flyash were higher at $15 \% \mathrm{RCA}$ than that of the BR flyash while still maintaining consistent increase with RCA content.

\subsection{Effect of alkali activator}

As shown in Figure 3, the UCS and E values decreased significantly with increase in $\mathrm{Na}_{2} \mathrm{SiO}_{3}$ for the $\mathrm{BR}$ and $\mathrm{SL}$ flyash. Interestingly, the highest values were shown to be at no $\mathrm{Na}_{2} \mathrm{SiO}_{3}$ content. For SL flyash, there were increases in the UCS and $\mathrm{E}$ values after $33 \% \mathrm{Na}_{2} \mathrm{SiO}_{3}$. On the other hand, the values of BR flyash based mixtures were more than that of SL for $0 \%$ and 33\% $\mathrm{Na}_{2} \mathrm{SiO}_{3}$. The dissolution of silicate in the subsequent additions (33\% and $50 \%)$ as in the case of BR flyash could be comparatively lower hence, the less UCS and E values. However, a microstructure analysis will give further insights into the nature of its kinematics at such effects. Further, more availability of Aluminum in BR flyash could be a reason of increase in strength and stiffness at $0 \% \mathrm{Na}_{2} \mathrm{SiO}_{3}$ as compared to SL flyash based mixtures. 

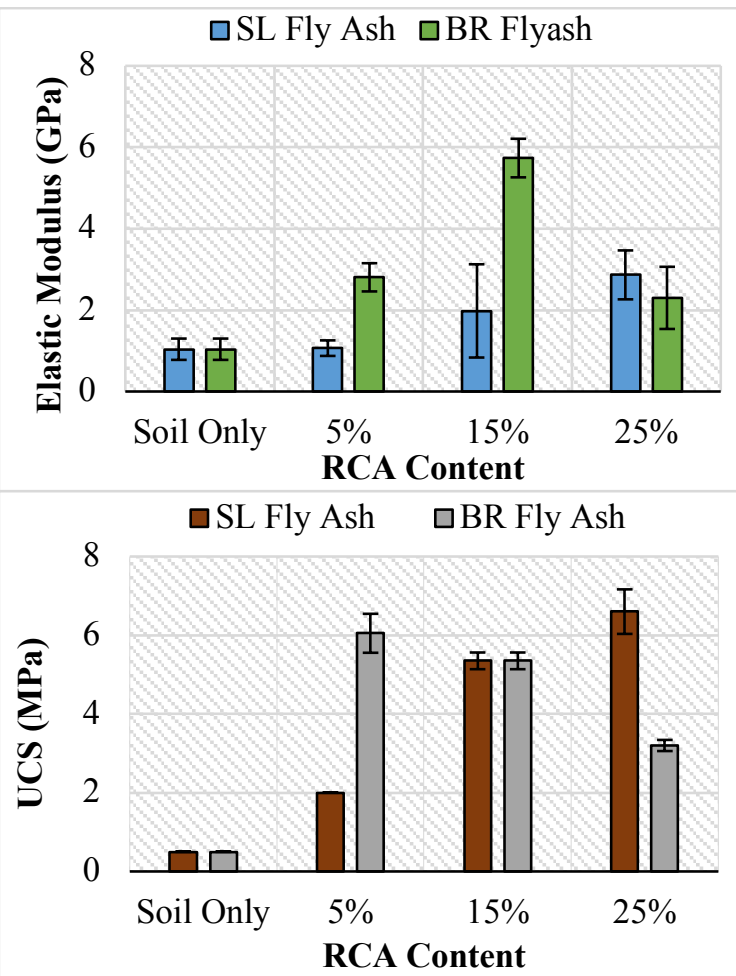

Fig. 2. Effect of RCA on elastic modulus and UCS at $15 \%$ flyash and $33 \% \mathrm{Na}_{2} \mathrm{SiO}_{3}\left(72 \mathrm{~h}\right.$ at $\left.60^{\circ} \mathrm{C}\right)$.

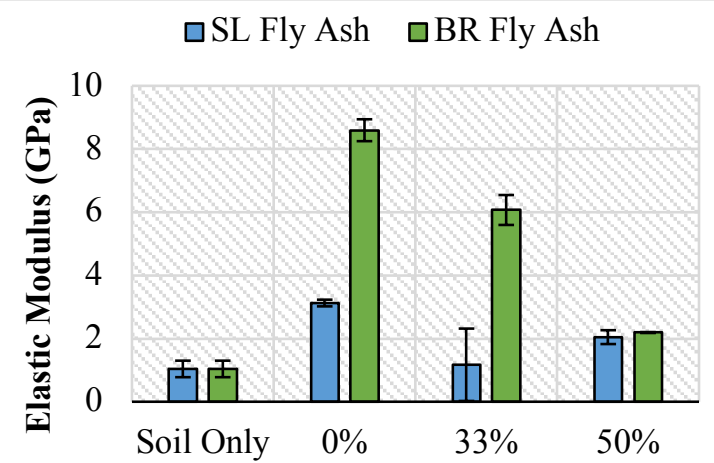

Sodium Silicate Content

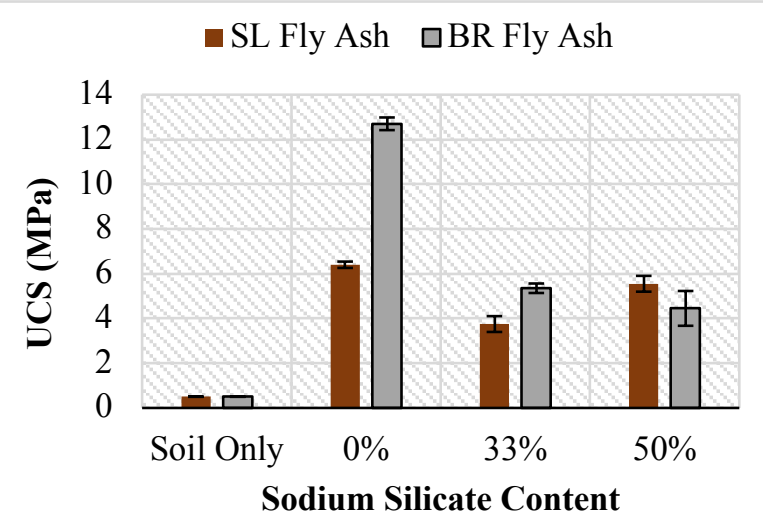

Fig. 3. Effect of $\mathrm{Na}_{2} \mathrm{SiO}_{3}$ on $\mathrm{E}$ and UCS values at $15 \%$ flyash and $15 \%$ RCA contents $\left(72 \mathrm{~h}\right.$ at $\left.60^{\circ} \mathrm{C}\right)$.

\subsection{Statistical analysis}

In this study, regression model was applied to find the relationships between the UCS of specimens and parameters affecting it. The UCS prediction model is as follow:

$y=\beta_{o}+\beta_{1} x_{i 1}+\beta_{2} x_{i 2}+\beta_{3} x_{j 1}+\beta_{44} x_{i 2}^{2}+\beta_{5} x_{i 2}^{2}+\beta_{6} x_{i 1} x_{i 2}$

Where, $\mathrm{y}$ is the UCS of specimen, $x_{i 1}, x_{i 2}$, and $x_{j 1}$, are mixed variables of flyash (0-25\%), RCA (0-25\%) and alkali ratio ( 0 to 1$)$, respectively while $\beta_{0}, \beta_{1}, \beta_{2}, \ldots \beta_{6}$ are coefficients of the prediction model.

The UCS response for Salt Lake and BR flyashes based on the model above is as shown below in equation 4 and 5 , respectively.

$y=0.178+0.016 x_{i 1}+0.031 x_{i 2}-0.83 x_{j 1}+0.570 x^{2}{ }_{j 1}$
$-0.0013_{x i 1} x_{i 2}$

$y=0.630+0.870 x_{i 1}+0.458 x_{i 2}-20.22 x_{j 1}+12.98 x_{j 1}^{2}$ $-0.037 x_{i 1} x_{i 2}$

The significant parameters affecting the strength of Soil-RCA geopolymer were obtained by performing analysis of variance (ANOVA) and the final predictor parameters were selected based on $\mathrm{R}^{2}$ and $\mathrm{P}$-value. The $\mathrm{P}$-values lesser than 0.05 indicates the parameters are statistically significant. Thus, from the analysis, the parameters namely the percentage of flyash, RCA and $\mathrm{Na}_{2} \mathrm{SiO}_{3}$ in the one-way interaction and the combination of factor, namely percentage of flyash/RCA content in the two-way interaction is statistically significant indicating their major effects on the strength of SoilRCA geopolymer. This response was observed in both flyash types. Predicted versus measured values for the models are shown in Figure 4.
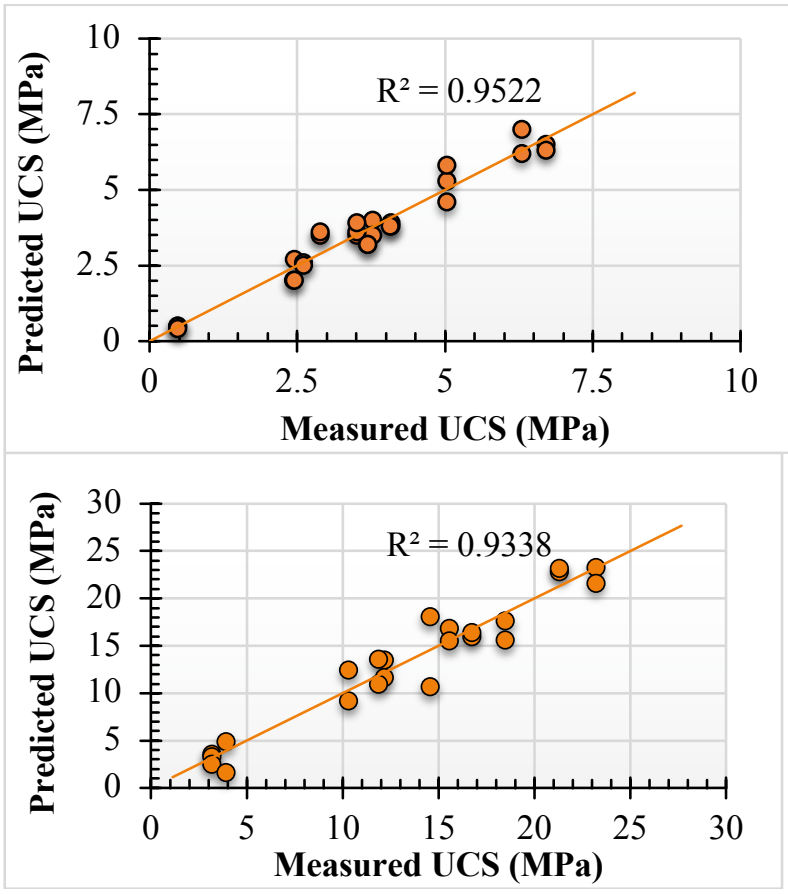

Fig. 4. Predicted versus measured UCS graphs for BR and SL flyash. 
Based on the model prediction and sensitivity, measured values, and cost effectiveness, the following geopolymer mixtures were selected for further testing. (1) $\mathrm{SL} 1: \quad 15 \% \mathrm{FA} 25 \% \mathrm{RCA} 33 \% \mathrm{Si}$, (2) SL2: 15\%FA15\%RCA $\% \% \mathrm{Si}$, (3) BR 1 : 15\%FA15\%RCA $0 \% \mathrm{Si}$, and (4) $25 \% \mathrm{FA} 15 \% \mathrm{RCA} 33 \% \mathrm{Si}$.

The cost effectiveness was determined according to requirement for alkali, and RCA addition. For instance, the mixtures with 15\% RCA or greater and 33\% Sodium Silicate or less are most preferred because they optimize the usage of RCA which is the central theme of this research with less focus or dependence on flyash. Apparently, using more recycled aggregates reduces the entire life cycle cost of the project.

\subsection{Mechanical characteristics of selected soil- geopolymer and soil-cement mixtures}

\subsubsection{UCS and elastic modulus}

It is evident from the results as shown in Figure 5a that the ultimate UCS and E of selected mixtures of BR flyash have higher values as compared to both soilcement and SR flyash based geopolymer mixtures. The BR1 mixture exhibits the highest values and has twice as much UCS and 4 times the E values as soil-cement mixtures. Such increases could be attributed to the flyash chemical content because the said mix (BR1) does not contain $\mathrm{Na}_{2} \mathrm{SiO}_{3}$ in its alkali mix. The aluminum content of BR flyash is much higher than the SL flyash, which help, is producing more aluminum-silicate geopolymer compounds. On the other hand, the 7-day cured soilcement mixtures showed significantly higher strength and modulus than the selected geopolymer mixtures. This increase is mainly due to the early hydration of cement in soil mixtures. However, the strength gain by the Soil-RCA geopolymer in 7 days at $25^{\circ} \mathrm{C}$ is minimal and could not even satisfy the Louisiana DOTD cementtreated design (CTD) criterion of $1.03 \mathrm{MPa}$ at 7 days curing period. This implies that such geopolymer mixtures require additional time to complete reaction and gain strength at room temperature.

\subsubsection{Indirect tensile strength}

The indirect tensile strength test (ITS) is used to evaluate the tensile properties of pavement materials, which can further be related to the cracking properties of the pavement. A higher tensile strength as shown in Table 3 for the BR geopolymer mixtures indicates a stronger cracking resistance mainly due to their improved resistance to tensile strain. This expectedly can be attributed to the presence of more Aluminum in the flyash particularly, the BR which strengthens the bonding amongst the Flyash, soil and RCA aggregate and as a result, the mixtures had the highest tensile strength due to higher Aluminum content.

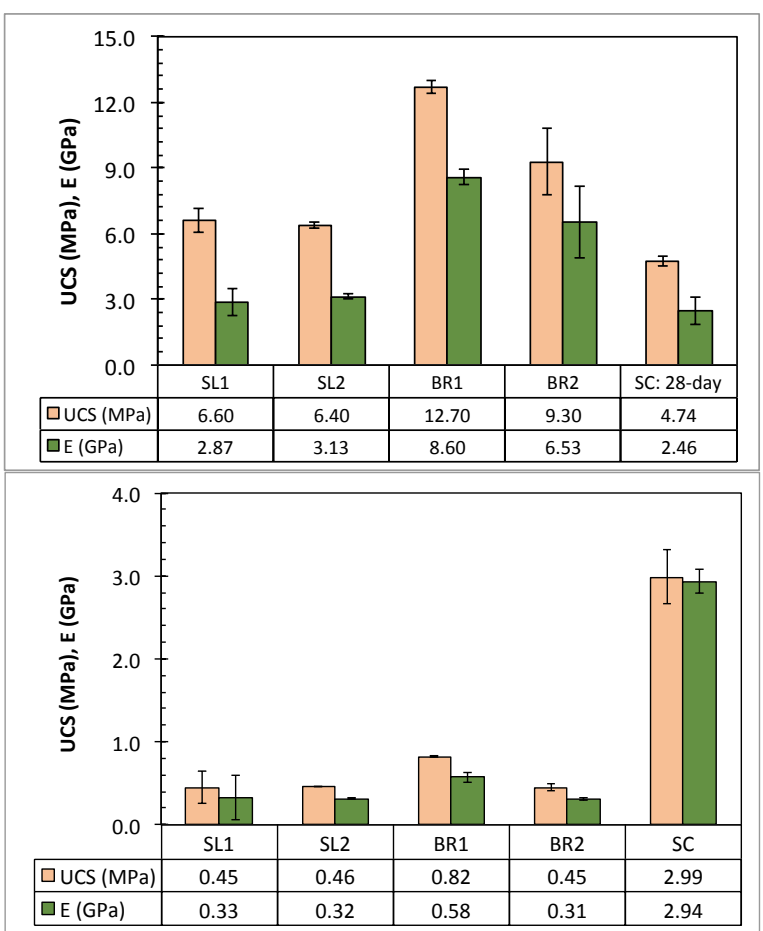

Fig. 5. a) UCS and E of soil-RCA geopolymer (72-h curing at $60^{\circ} \mathrm{C}$ ) and soil-cement $\left(\mathrm{SC}-28\right.$-day at $\left.25^{\circ} \mathrm{C}\right)$, b) UCS and E of soil-RCA geopolymer and soil-cement both at 7 days curing at $25^{\circ} \mathrm{C}$.

Table 3. Summary of ITS for the selected Soil-RCA geopolymer and soil-cement mixtures.

\begin{tabular}{|c|c|c|c|c|c|}
\hline Mix type & SL1 & SL2 & BR1 & BR2 & $\begin{array}{c}\text { SC: Soil- } \\
\text { Cement }\end{array}$ \\
\hline $\begin{array}{c}\text { Curing } \\
\text { Type }\end{array}$ & \multicolumn{4}{|c|}{ Oven Curing- $72 \mathrm{~h} @ 60^{\circ} \mathrm{C}$} & $\begin{array}{c}28 \text {-day } @ \\
25^{\circ} \mathrm{C}\end{array}$ \\
\hline $\begin{array}{c}\text { Average } \\
\text { (MPa) }\end{array}$ & 0.560 & 0.530 & 1.260 & 0.930 & 0.500 \\
\hline $\begin{array}{c}\text { Standard } \\
\text { Deviation }\end{array}$ & 0.009 & 0.020 & 0.061 & 0.035 & 0.003 \\
\hline
\end{tabular}

\subsubsection{Durability test}

Results of durability test (Table 4) indicated that selected geopolymer mixtures \& soil-cement have passed durability criteria as per ASTM standard, which requires that the material specimen cannot exceed a change in volume of $2 \%$ or a change in mass of $10 \%$. This is very unexpected because the 7-day strengths for geopolymers were all lower than $1.03 \mathrm{MPa}$ as a DOTD criterion for CTD of soil mixtures for road base and subbase layers. Even though both mixture types passed durability criteria geopolymer mixtures exhibited lower volume change $\&$ mass loss relative to the soil-cement mixtures.

Table 4. Durability results for the selected Soil-RCA geopolymer and soil-cement mixtures.

\begin{tabular}{|c|c|c|c|c|c|}
\hline Mixture Type & SL1 & SL2 & BR1 & BR2 & $\begin{array}{c}\text { SC: Soil- } \\
\text { Cement }\end{array}$ \\
\hline $\begin{array}{c}\text { Volume Change } \\
(\%),<\mathbf{2 \%}\end{array}$ & 1.00 & 1.41 & 1.39 & 1.27 & 1.50 \\
\hline $\begin{array}{c}\text { Mass Change } \\
(\%),<\mathbf{1 0 \%}\end{array}$ & 4.25 & 4.36 & 4.43 & 4.40 & 6.25 \\
\hline
\end{tabular}

All mixtures were cured for 7 days at room temperature of $25^{\circ} \mathrm{C}$. 


\section{Conclusions and recommendations}

Based on the laboratory test results, the following conclusions were drawn:

1. An increase in flyash and RCA content increased the UCS and E of the Soil-RCA geopolymer mixtures for both flyash types. Flyash content of $25 \%$ and RCA of $15 \%$ exhibited optimum UCS and E values. On the other hand, the addition of sodium silicate had a decreasing effect on UCS and E values of Soil-RCA geopolymer mixtures.

2. The ultimate UCS, E, and ITS of the selected geopolymer mixtures at 72 -h curing $\left(60^{\circ} \mathrm{C}\right)$ were considerably higher than the 28-day room temperature cured soil-cement mixture. The BR flyash-based geopolymer mixtures exhibited the highest values. On other hand, the 7-day room temperature curing of Soil-RCA geopolymer mixtures yielded much lower values than the soilcement mixtures. This indicated that Soil-RCA geopolymer needed extra time to cure and gain strength at room temperature.

3. Interestingly, the Soil-RCA geopolymer mixtures cured for 7 days at room temperature showed better durability performance than the soil-cement mixtures cured for 7 days, even though the 7-day strength of the geopolymer mixtures were much less than the soil-cement mixtures.

This research study has therefore proven that SoilRCA geopolymer mixtures exhibit better ultimate strength, modulus, and durability characteristics relative to the soil-cement mixtures. However, such mixtures required more curing time at room temperature to achieve needed strength. In order to further optimize the practical applications of this technology in the field, other variables such as molarity of alkali activator, curing conditions, early strength development at room and ambient temperature, gradation of RCA and shrinkage characteristics need be investigated.

The authors would like to thank Tran-SET (Project No: 18GTLSU10), National Science Foundation (NSF) under Grant No: 1757786, and University of Louisiana at Lafayette for funding this research. Special thank is also extended to Mark LeBlanc for assisting in experimentation. Any opinions, findings, and conclusions or recommendations expressed in this material are those of the author(s) and do not necessarily reflect the views of the funding agencies.

\section{References}

1. State of Louisiana Department of Transportation and Development. Louisiana standard specifications for roads and bridges. Part III, 305.04, 2006.

2. Gautreau, G., Zhang, Z., and Wu, Z. (2011). Accelerated loading evaluation of subbase layers in pavement performance. Louisiana Transportation Research Center, Final Report No. FHWA/LA.09/468.

3. Marceau, M., Nisbet, M., and VanGeem, M. (2007). Life Cycle Inventory of Portland Cement Concrete.
PCA R\&D Serial No. 3011. Portland Cement Association, Skokie, IL.

4. Davidovits, J. (2008). Geopolymer Chem. and Applications, 2nd ed., Inst. Geopoly., Saint-Quentin, France.

5. Hardjito, D., Wallah, S., Sumajouw, D.M.J., and Rangan, B.V. (2004). On the Development of Fly Ash-Based Geopolymer Concrete. ACI Materials Journal, vol. 101(6), 467-472.

6. Rangan, B.V. (2008). Fly ash-Based Geopolymer Concrete, Research Report GC-4, Faculty of Engineering, Curtin University of Technology, Perth, Australia.

7. EFNARC. The European Guidelines for SelfCompacting Concrete Specification. May 2005.

8. Davidovits, J., and Sawyer, L. Early high-strength mineral polymer. Pyrament Inc. US Patent 509985A, 4/9/1985.

9. Hambling, D. (2009). Cool Under Pressure: Geopolymers Offer Diverse Structural Benefits." Defense Technology International, September/October, 2009. Defense Tech. International, Washington, DC.

10. Han, C., Pyzik, A., and Liu, J. (2012). Modified Geopolymer compositions, processes and uses. Dow Global Technologies LLC, EP 2438027 A2, Apr 11, 2012.

11. Annual Asphalt Pavement Industry Survey on Recycled Materials and Warm-Mix Asphalt Usage: 2009-2012, 3rd Annual Asphalt Pavement Industry Survey (AAPI) IS-138 Produced December 2013

12. Environmental Protection Agency (EPA, 2017). www.epa.gov/coalash/coal-ash-reuse.

13. Deal, T.A. What it costs to recycle concrete: C\&D Debris Recycling, Sept/Oct., 1997, 10-13.

14. Arora, S., Aydilek, A.H. (2005). Class F Fly-AshAmended Soils as Highway Base Materials. Journal of Materials in Civil Engineering, 2005, 17(6) DOI: 10.1061/(ASCE)0899-1561.

15. S. H. S.-L. S. Patimapon Sukmak. Strength development in clay-fly ash geopolymer. Construction and Building Materials, vol. 40, no. 566-574, p. 11, 2013.

16. Phummiphan, I., Horpibulsuk, S., Rachan, R., and Arulrajah, A. (2018). High calcium fly ash geopolymer stabilized lateritic soil and granulated blast furnace slag blends as a pavement material. Hazardous Materials, 341, 257-267.

17. Cristelo, N., Glendinning, S., Miranda, T., Oliveira, D., and Silva, R. (2012). Soil Stabilization using alkaline Activation of Fly ash for self-compacting rammed Earth Construction. 36, 727-735.

18. Zumrawi, M.M. and Mohammed, M.H. (2016). Effect of Fly Ash on the characteristics of expansive soils in Sudan. p. 7.

19. Parti, P.S. and Das, S. K. (2014). Suitability of alkali activated fly ash binder as a stabilizing agent for expansive soils.

20. Rios, S. and Fonseca, A.V.D. (2015). Alkali activated soil-ash mixtures. Geo-technical Engineering for Infrastructure and Development. 
21. Rios, S., Cristelo, N., Fonseca, A.V.D., and Ferreira, C. (2011). Structural Performance of Alkali activated Soil ash Versus Soil Cement. American Society of Civil Engineers.

22. Cruz, N., Rios, S., Fonseca, A.V.D., and Rodrigues, C. (2017). Mechanical and Durability Properties of a soil stabilized with alkali-activated cement, European J. of Environmental and Civil Engineering, p. 37.

23. Cristelo, N., Glendinning, S., and Pinto, A.T. (2011). Deep Soft soil improvement by alkaline activation. Institute of Civil Engineers.

24. Vargas, A.S.d., Dal Molin, D.C.C., Masuero, A.B, Vilela, A.C.F, Castro-Gomes, J., Gutierrez, R.M.d. (2014). Strength development of alkali activated flyash produced with combined $\mathrm{NaOH}$ and $\mathrm{CA}(\mathrm{OH})_{2}$ activators. Cement and concrete composites, 341-349. 